\title{
Approach to Solid Liver Masses in the Cirrhotic Patient
}

\author{
Nimer Assya, b, e, Najib Assy ${ }^{a}$, Nir Samuel ${ }^{a}$, Aracdi Lerman ${ }^{c}$, William Nseir ${ }^{\mathrm{d}}$
}

\begin{abstract}
Background: Liver masses in cirrhosis are increasingly being recognized with the use of new imaging modalities. The majority of these lesions are detected by ultrasound, enhanced CT and MRI. The most likely diagnosis of a solid liver lesion in a cirrhotic liver is hepatocellular carcinoma, followed by high grade or low grade dysplastic nodule, and cholangiocarcinoma. Lymphoma and liver metastasis are extremely rare. Diagnosis is made by contrast enhanced ultrasound, multi detector (MDCT) and MRI. Fine needle core biopsy (FNCB) or aspiration (FNAB) or both may be required in doubtful cases. If uncertainty persists on the nature of the lesion, surgical liver resection is recommended. This review discusses the main characteristics of the most common solid liver masses in cirrhotic patient.
\end{abstract}

Keywords: Liver mass; Hepatic nodule; Tumor; Lesion; Cirrhosis; Hepatocellular carcinoma; Cholangicarcinoma; Dysplasia; Metastasis; Fine needle aspiration; Core biopsy

\section{Introduction}

Liver masses are increasingly being recognized with the widespread use of imaging modalities such as ultrasonography, computed tomography, and magnetic resonance imaging [1]. The most important initial question is whether cirrhosis or an extra hepatic disorder may lead to the development of a focal liver lesion, such as a regenerative nodule,

Manuscript accepted for publication September 17, 2009

${ }^{a}$ Liver Unit, Ziv Medical Center, Safed, Israel

${ }^{\mathrm{b}}$ Technion Institute, Haifa, Israel

${ }^{\mathrm{c}}$ Department of Radiology, Ziv Medical Centre, Safed, Israel

${ }^{\mathrm{d}}$ Holy Family Hospital, Nazareth, Israel

${ }^{\mathrm{e}}$ Corresponding author: Liver Unit, Ziv Medical Center, Safed 13100,

Israel. assy.n@ziv.health.gov.il; assy.nimer@gmail.com

doi:10.4021/gr2009.09.1314 hepatocellular carcinoma, and a metastatic mass or infectious process. An accurate history and physical examination are essential to diagnosis and treatment for solid liver mass. A history of post viral cirrhosis due to $\mathrm{HBV}$ or $\mathrm{HCV}$ may point to hepatocellular carcinoma (HCC) [1]. Use of oral contraceptives or anabolic steroids can be related to hepatic adenoma [2]. Alcohol use and vinyl chloride exposure are related to angiosarcoma [3]. Primary sclerosing cholangitis, Caroli's disease and choledochal cysts are associated with cholangiocarcinoma [4]. A previous neoplasm or chemotherapy increases the suspicion of metastatic disease. Physical examination should look for liver tenderness, lymphadenopathy, hepatomegaly, splenomegaly, ascites, other stigmata of chronic liver disease, or general deterioration signs (fever, weight loss). High alkaline phosphatases, high lactate dehydrogenase (LDH), low albumin, high prothrombine time, and iron overload are non specific but may suggest underlying cirrhosis or an infiltrative process [5].

A liver mass in a cirrhotic liver should be viewed as an HCC until proven otherwise. The diagnosis of liver masses in a cirrhotic liver includes malignant and benign lesions [6-8] (Table 1). After detecting hepatic mass on ultrasound, the mass can be characterized with contrast enhanced ultrasound, multi detector computed tomography or magnetic resonance imaging. Each technique has its advantages and disadvantages. The choice of modality depends on many factors including cirrhosis, fatty infiltration, and number of nodules. This review discusses the various characteristics of the most common solid liver masses (lesions) in cirrhotic patient including value of tumor markers, imaging techniques, fine needle aspiration or biopsy, dilemmas and pitfalls, clinical differential diagnosis of malignant and benign lesions, liver biopsy and liver mass resection.

\section{Tumor markers}

Alpha fetoprotein (AFP), PIVKA-II (protein induced by vitamin $\mathrm{K}$ absence or antagonist II), desgamma-carboxy prothrombin (DCP) are tumor markers for HCC [9]. The combination of Ca 19-9 + CEA markers gave an accuracy of $86 \%$ in diagnosis of cholangiocarcinoma [10]. AFP values 
Table 1. Accuracy and key features of imaging techniques in the diagnosis of most common liver masses in cirrhosis

\begin{tabular}{|c|c|c|c|c|c|}
\hline Lesions & $\begin{array}{l}\text { US- US Doppler, } \\
\text { Contrast ultrasound }\end{array}$ & Triphasic Dynamic CT & MRI & PET SCAN & CT-Angiography \\
\hline HCC & $\begin{array}{l}+ \\
\text { Hypo or hyper echoic } \\
\text { Doppler: hyper } \\
\text { vascular. } \\
\text { index and flow high, } \\
\text { spectral broadening }\end{array}$ & $\begin{array}{l}++ \\
\text { hyper vascular, often } \\
\text { irregular borders } \\
\text { Heterogeneous> } \\
\text { Homogeneous } \\
\text { abnormal internal vessel } \\
\text { Hallmark feature is } \\
\text { arterial hypervascular- } \\
\text { and venous wash-out } \\
\text { SS } 52-54 \%\end{array}$ & $\begin{array}{l}+++ \\
\text { hyper vascular } \\
\text { Poor different: Hypo } \\
\text { intense T-1, Hyper } \\
\text { intense T2; } \\
\text { Well different: Hype } \\
\text { intense T-1, Iso intense } \\
\text { T-2 } \\
\text { SS 53-78\% }\end{array}$ & $\begin{array}{l}+ \\
\text { Increased uptake. } \\
\text { but many HCC } \\
\text { do not show } \\
\text { uptake at PET }\end{array}$ & $\begin{array}{l}++++ \\
\text { Hyper vascular } \\
\text { Av shunting } \\
\text { angiogenesis }\end{array}$ \\
\hline Cholangio -CA & $\begin{array}{l}\text { Bile duct dilatation } \\
\text { if major ducts are } \\
\text { involved } \\
\text { Intrahepatic CCC: no } \\
\text { bile dilatation }\end{array}$ & $\begin{array}{l}\text { Hypo dense lesion } \\
\text { Delayed enhancement }\end{array}$ & $\begin{array}{l}\text { Hypo intense T1 } \\
\text { Hyper intense T2 } \\
\text { MRCP is useful }\end{array}$ & $\begin{array}{l}\text { SS 93\% } \\
\text { Increase uptake }\end{array}$ & Hyper vascular \\
\hline Metastasis & $\begin{array}{l}+ \\
\text { SS 40-70 \% } \\
\text { hypo echoic to hyper } \\
\text { echoic; Doppler; } \\
\text { low index and flow; } \\
\text { presence of spectral } \\
\text { broadening }\end{array}$ & $\begin{array}{l}+++ \\
\text { SS } 49-74 \% \\
\text { complete ring } \\
\text { enhancement }\end{array}$ & $\begin{array}{l}+++ \\
\text { SS } 68-90 \% \\
\text { Low intensity T-1 } \\
\text { High intensity T-2 }\end{array}$ & $\begin{array}{l}+++++ \\
\text { SS 90-100\% } \\
\text { colon, pancreas }\end{array}$ & $\begin{array}{l}++++ \\
\text { SS 88-95\% } \\
\text { hyper vascular }\end{array}$ \\
\hline Haemangioma & $\begin{array}{l}++ \\
\text { Hyper echoic } \\
\text { Doppler: low flow, } \\
\text { low index, absence of } \\
\text { spectral broadening }\end{array}$ & $\begin{array}{l}\text { Peripheral puddles, } \\
\text { fill in from periphery, } \\
\text { enhancement on } \\
\text { delayed scan }\end{array}$ & $\begin{array}{l}++++ \\
\text { Peripheral enhancement } \\
\text { centripetal progression } \\
\text { HyperintenseT2, } \\
\text { hypo intense } \mathrm{T} 1 \\
\mathrm{SS}>95 \% \text {, } \\
\text { SP } 95 \%\end{array}$ & No uptake & $\begin{array}{l}\text { Cotton wool pooling of } \\
\text { contrast, normal vessels } \\
\text { without AV shunt, } \\
\text { persistent enhancement }\end{array}$ \\
\hline Focal fatty liver & $\begin{array}{l}+ \\
\text { hyper echoic, no } \\
\text { mass effect, no vessel } \\
\text { displacement }\end{array}$ & $\begin{array}{l}++ \\
\text { Sharp interface } \\
\text { Low density }(<40 u)\end{array}$ & +++ & No uptake & normal finding \\
\hline Adenoma & $\begin{array}{l}+ \\
\text { Heterogeneous } \\
\text { Hyper echoic } \\
\text { If haemorrhage: } \\
\text { anechoic centre. } \\
\text { Doppler: variable } \\
\text { flow and spectral } \\
\text { broadening }\end{array}$ & ++ & $\begin{array}{l}++ \\
\text { Capsule, } \\
\text { Hyper intense } \mathrm{T} 1 \\
\text { (intra lesion fat ) }\end{array}$ & $\begin{array}{l}\text { no uptake } \\
\text { uptake if } \\
\text { degeneration to } \\
\text { HCC }\end{array}$ & $\begin{array}{l}++ \\
\text { Hyper vascular } \\
\text { Large peripheral } \\
\text { Vessel. Central scar } \\
\text { if haemorrhage }\end{array}$ \\
\hline
\end{tabular}

+, degree of accuracy; SS sensitivity; SP specificity; a; Intraoperatrive ultrasound, contrast ultrasound and EUS are highly sensitive to detect liver mass; From Assy N, World J Gastroenterol. 2009;15:3217-27. 
Table 2. Accuracy of tumor markers in the diagnosis of HCC

\begin{tabular}{|c|c|c|c|c|c|c|}
\hline & $\begin{array}{l}\text { Normal } \\
\text { value }\end{array}$ & $\begin{array}{l}\text { Sensitivity } \\
\%\end{array}$ & $\begin{array}{l}\text { Specificity } \\
\%\end{array}$ & $\begin{array}{l}\text { PPV } \\
\%\end{array}$ & $\begin{array}{l}\text { NPV } \\
\%\end{array}$ & $\begin{array}{l}\text { Diagnostic } \\
\text { accuracy } \\
\%\end{array}$ \\
\hline $\begin{array}{l}\text { AFP } \\
\text { (ng/dL) }\end{array}$ & 20 & 55 & 97 & 95 & 69 & 77 \\
\hline $\begin{array}{l}\text { CEA } \\
\text { (ng/dL) }\end{array}$ & 7 & 22 & 78 & 48 & 51 & 51 \\
\hline $\begin{array}{l}\text { TPA } \\
\text { (U/L) }\end{array}$ & 90 & 70 & 61 & 62 & 70 & 66 \\
\hline $\begin{array}{l}\text { DCP } \\
(\mathrm{AU} / \mathrm{ml})\end{array}$ & 0.09 & 53 & 88 & 88 & 66 & 71 \\
\hline
\end{tabular}

Des-gamma-carboxy prothrombin (DCP). Tissue polypeptide antigen (TPA), alpha fetoprotein (AFP), carcinoembryonic antigen (CEA), From Grazi GL, liver transplantation and surgery 1995;1:249-255. [9]

higher than $400 \mathrm{ng} / \mathrm{ml}$ in the presence of cirrhosis is indicative of HCC. Thirty percent of patients with HCC less than 2 $\mathrm{cm}$ have normal AFP, twenty percent of HCC do not produce AFP, and levels between $20-250 \mathrm{ng} / \mathrm{ml}$ are frequently seen in regenerating nodules or viral cirrhosis [11]. A rising AFP over time is virtually diagnostic of HCC. The serum level of at least 1 of the tumor markers was elevated in $88 \%$ of patients with proven malignancy, and in $57 \%$ of cases the elevation was marked. Early lesions may have elevated tumor markers in fewer than $30 \%$ of cases [12]. The sensitivity, specificity, positive and negative predictive value of tumor markers in the diagnosis of HCC is shown in Table 2 [9].

The limitation of developing HCC markers is probably due to heterogeneity assay methods and result reporting, limited analysis of demographics and causes of liver disease as covariates in the expression of these biomarkers. In addition, these molecules need to be validated and cost-effectiveness especially those markers proposed as diagnostic or prognostic role. Further studies are needed to confirm the roles and to validate these biomarkers.

\section{Imaging techniques}

Key features of imaging technique in the diagnosis of liver mass are shown in Table 1.

The gold standard for detection and location of focal lesions in cirrhosis is enhanced MRI or triple phase dynamic spiral CT [13]. Conventionally a triple phase CT scan includes unenhanced, arterial and venous phases. The fourth phase is a delayed venous scan (quadruple phase multi detector com- puted tomography, MDCT) [13]. This is only required for small lesions thought to be HCC or cysts and hemangiomas. A single imaging modality can be sufficient in cases such as metastasis which show interval development or progression. CT Porto angiography is one of the most sensitive imaging for metastasis but it is an examination that is performed in high selected cases, in few institutions and not for all types of liver lesions [14]. FDG PET CT scan is not very useful for HCC and therefore is not the best imaging modality to distinguish benign from malignant lesions [15]. Ultrasound

Table 3. Accuracy of magnetic resonance imaging (MRI) and spiral computed (CT) in the diagnosis of liver mass (nodule)

\begin{tabular}{lll}
\hline & $\begin{array}{l}\text { MRI } \\
\%\end{array}$ & $\begin{array}{l}\text { CT } \\
\%\end{array}$ \\
\hline Sensitivity & 85 & 70 \\
Specificity & 71 & 86 \\
Positive predictive value & 92 & 95 \\
Negative predictive value & 56 & 43 \\
Diagnostic Accuracy & 82 & 74 \\
\hline
\end{tabular}

From: de Ledinghen: Eur J Gastroenterol Hepatol, 2002;14:159165. [19] 
Table 4. The sensitivity (\%) of FNA cytology, needle core biopsy, and combined FNA/FNCB in malignant and in benign liver lesions

\begin{tabular}{llll}
\hline Biopsy Site & $\begin{array}{l}\text { FNA } \\
\%\end{array}$ & $\begin{array}{l}\text { FNCB } \\
\%\end{array}$ & $\begin{array}{l}\text { Combined } \\
\%\end{array}$ \\
\hline Liver Metastasis & 86 & 83 & 88 \\
$\begin{array}{l}\text { Hepatocellular } \\
\text { Carcinoma }\end{array}$ & 100 & 89 & 100 \\
$\begin{array}{l}\text { Benign Liver } \\
\text { Lesions }\end{array}$ & 100 & 89 & 100 \\
\hline
\end{tabular}

FNA, fine needle aspiration. FNCB, needle core biopsy, From: Stewart CJ; J Clin Pathol. 2002; 55: 93-97. [20]

contrast agents and MRI using iron or gadolinium contrast better detect smaller lesions, satellite lesions or distant metastasis [16-18]. Radiographic characteristics favoring hepatocellular carcinoma include the presence of a lesion with different densities, arterial hyper vascularisation and venous wash-out. The diagnostic accuracy of MRI and computed tomography (CT), sensitivity, and specificity in the diagnosis of liver mass is shown in Table 3 [19].

\section{Fine needle aspiration and core biopsy}

Fine needle aspiration and core biopsy (FNAB) is safe, accurate and cost effective. Its specificity approaches $100 \%$ and its sensitivity is $67-100 \%$ [20]. FNAB under CT or under ultrasound (in an appropriate location) is the method of choice. FNAB is superior to fine needle core biopsy (FNCB), however, the methods are complementary, i.e., FNAB and FNCB have an accuracy of 78\% separately and $88 \%$ when considered in combination [21-22]. However, many pathologists would state that core biopsies are much preferred over needle biopsies for diagnosis of hepatic mass, since well differentiated HCC cannot be separated from normal liver. Complications (mostly haemorrhage) are rare with $0.5 \%$ minor complications and $0.05 \%$ major complications [23]. Another concern is the seeding of tumor. Blind FNAB is diagnostic in more than $50 \%$ of cases which increases to $65 \%$ when performing a second pass [24]. An additional $5-10 \%$ of tumors will be recognized if cell block is obtained. Markers commonly used for immunohistochemical staining in the evaluation of hepatic tumors include polyclonal CEA, cytokeratin 8/18 pair, cytokeratin 7/20, hep par 1, Glypican-3, and AFP for hepatocellular carcinoma [25]; cytokeratin $7 / 19$, cytokeratin $7 / 20$, B-HCG, CEA, and mucin-1 for cholangicarcinoma [26], CD 34, CD31, and factor V111 for hemangiendothelioma; and cytokeratin $7 / 20$ for metastatic liver disease. The sensitivity and specificity of FNA cytol- ogy, needle core biopsy and combined FNA/FNCB in the diagnosis of malignant and benign liver lesions are shown in Table 4 [20].

\section{Clinical dilemmas and pitfalls}

Screening for HCC in cirrhotic liver includes ultrasound plus AFP levels every 6 months. The AASLD guidelines recommend ultrasound only [27].

\section{Liver mass more than $2 \mathrm{~cm}$}

Lesions more than $2 \mathrm{~cm}$ need just one imaging technique showing typical findings (enhancement in the arterial phase and washout in the portal venous phase) or one imaging technique and AFP levels higher than $400 \mathrm{ng} / \mathrm{ml}$ in order to make a non-invasive diagnosis of HCC [11]. More than $80 \%$ of over $2 \mathrm{~cm}$ in a cirrhotic liver are HCC [28]. An elevated AFP confirms the diagnosis. If AFP is normal, further imaging will be diagnostic (triphasic CT, MRI) [11]. If there is still doubt, FNCB may be indicated.

\section{Liver mass less than $2 \mathrm{~cm}$}

Seventy-five percent of masses which are less than 2 $\mathrm{cm}$ in a cirrhotic liver are HCC [29]. Lesions smaller than 2 $\mathrm{cm}$ are divided into larger and smaller than $1 \mathrm{~cm}$. The larger nodules should be diagnosed and the small lesions should be surveyed every 3 months $[27,30]$. Nodules more than $1 \mathrm{~cm}$ but less than $2 \mathrm{~cm}(1-2 \mathrm{~cm})$ need diagnostic workup with two coincident or serial imaging techniques (among US, CT, and MRI with IV contrast injection) rather than just proceeding with biopsy. If two of these techniques show typical imaging criteria, then it is possible to diagnose HCC. Nodules less than $1 \mathrm{~cm}$ need screening follow up every 3 months. A small nodule can be pre-neoplastic or benign. However, Caturelli showed that $69 \%$ of new nodules in a cirrhotic liver are malignant [29]. Moreover, liver cell dysplasia is found in $60 \%$ of cirrhotic livers containing hepatocellular carcinoma and in only $10 \%$ of non-cirrhotic livers [31]. Because of the risk of tumor seeding, biopsy should be avoided if surgical resection is possible. Nine percent to $37 \%$ of $\mathrm{HCC}$ are resectable at diagnosis. Contraindications to resection are: decompensated cirrhosis, extra-hepatic metastases, involvement of hepatic nodes or inferior vena cava (IVC), or bilobar extension [32].

\section{Increased AFP without detectable liver mass on liver im- aging}

In this case repeated dynamic CT or MRI every 3 months is the rule $[12,33]$. An elevated AFP does not necessarily diagnose $\mathrm{HCC}$, especially in patients with $\mathrm{HCV}$ who 
commonly have modest elevation of AFP without HCC. A marked AFP is helpful but modest elevations would certainly not be an indication for OLT in the absence of a liver mass.

\section{Clinical differential diagnosis of the most like- ly lesions in liver cirrhosis}

\section{Malignant lesions}

\section{Hepatocellular carcinoma}

$\mathrm{HCC}$ is a common tumor with an incidence of $1-6 \%$ among cirrhotic patients [34]. Risk factors include cirrhosis, alcohol, HBV, HCV, metabolic liver diseases, environmental carcinogens, hormonal treatments and smoking [35]. About $90 \%-95 \%$ of HCC arise in cirrhotic livers. Autopsy studies indicate that $20-40 \%$ of patients with cirrhosis have HCC. The tumor size and severity of liver disease influences survival rate. Patients with tumor less than $5 \mathrm{~cm}$ have a survival of $80 \%$ at 1 year and $20 \%$ at 3 years [32]. New abdominal pain, recent hepatomegaly, hemoperitoneum, persistent fever or weight loss in a cirrhotic patient should raise suspicion for HCC. Laboratory results that characterize HCC are a sudden increase in alkaline phosphatases, an increased ratio AST/ ALT, an erythrocytosis, a persistent leukocytosis, recurrent hypoglycaemia, hypercholesterolemia and hypercalcemia. The last four findings are paraneoplastic manifestations [32] together with ectopic hormonal syndrome, hypertrophic osteoarthropathy, and porphyria cutana tarda [36]. Complications of HCC include obstructive jaundice, and rupture of HCC (hemoperitonium; 60 - 90\% mortality)

\section{Dysplastic nodule}

Dysplastic nodule often occurs within regenerative cirrhotic nodules. They can show low or high grade dysplasia. A progression from regenerative nodule with low grade dysplastia, high grade dysplasia, well differentiated and poorly differentiated HCC is possible [37]. MRI best differentiates this iso-or hypo- intense lesion from hyper intense HCC [38]. In difficult cases, histology is required after liver resection or liver transplant. If HCC cannot be confirmed, repeat investigation later.

\section{Cholangiocarcinoma}

Cholangiocarcinoma accounts for $20 \%$ of primary liver tumors, arises as adenocarcinoma, papillary or mucinous carcinomas [39]. Risk factors are cirrhosis, primary sclerosing cholangitis (PSC, 10\%), bile duct adenoma, choledochal cysts, biliary papillomatosis, Caroli's disease and liver fluke [40]. Jaundice is the most frequent clinical presentation, and rapidly increasing bilirubin associated to weight loss predicts cholangiocarcinoma [41]. Tumor markers CEA, CA-19-9 or AFP may be elevated. CA 19-9 level higher than 100 has $89 \%$ sensitivity and $86 \%$ specificity [42]. There are three anatomic subtypes: peripheral intrahepatic $15 \%$, perihilar central (Klatskin tumor) $60 \%$ and distal common bile duct $25 \%$. Peripheral cholangiocarcinoma resembles HCC without cirrhosis. The central hilar and distal types are associated to sclerosing cholangitis, inflammatory bowel disease or other chronic biliary disease. US and CT show marked intrahepatic duct dilatation [43]. An abrupt change in the calibre of the bile duct suggests malignancy [44]. Digital image analysis (DIA) and fluorescent in situ hybridization (FISH) are more sensitive than routine standard brush cytology in the diagnosis of cholangiocarcinoma. ERCP, percutaneous trans hepatic cholangiography (PTC) and magnetic resonance cholangiopancreatography (MRCP) assess the resectability of the tumor. PET CT stages these tumors with a sensitivity of $93 \%$. The suggested screening includes US, CEA and CA 19-9 every 6 months, ERCP and brush cytology if there is biliary stenosis [45].

\section{Lymphomas}

Liver involvement is common in Hodgkin's disease including lymphoma infiltration (diffuse small nodules or large masses), drugs, viral hepatitis, and sepsis. Cholestasis is uncommon and vanishing bile duct syndrome has been described [46]. The differential diagnosis includes reactive infiltrate and T-cell lymphomas. Primary hepatic lymphoma is rare and can present as solitary or multiple masses, as a diffuse hepatic involvement with hepatomegaly, or as hepatic failure with elevated LDH [47].

\section{Liver metastasis}

The liver is the most common site of metastasis from the gastrointestinal tract, pancreas, breast, and lung [48]. Only $20 \%$ of liver metastases present as solitary lesions. The involvement of both hepatic lobes is the most common. Although, liver metastasis is a rare finding in cirrhosis, on CT-scan, colorectal metastases appear as low attenuation lesions, often with irregular margins and necrotic centres [49]. During the early vascular phase of dynamic CT, metastasis appears with increased enhancement. The sensitivity of CT $(85 \%)$ can be augmented by CT arterial portography [50]. Intra operative ultrasound has excellent sensitivity and specificity for colorectal adenocarcinoma metastasis [51]. The most promising imaging modality is PET CT with FDG that accumulates in cells with hyper metabolism. Colon, lung, and breast cancer can be staged with PET CT with sensitivity $92-100 \%$ and specificity $85-100 \%$ [52]. In metastatic colorectal carcinoma, the prognosis has improved following surgical resection. Contraindications to resection include: more than 4 liver metastases, extra hepatic spread and in- 
volvement of hepatic lymph nodes or vascular invasion. Calcified metastases from stomach, pancreas, lung and breast to the liver are extremely rare. Guided FNA will help identifying the primary lesion [53].

Other very rare malignant tumors in cirrhotic liver includes: epithelioid hemangioendothelioma, cystadenocarcinoma, and angiosarcoma, undifferentiated sarcoma of the liver, rhabdomyosarcoma, fibro sarcoma, and leiomyosarcoma.

\section{Benign lesions}

\section{Haemangioma}

Haemangioma is found in $20 \%$ of the general population, more commonly in women [54]. The majority are asymptomatic. Giant haemangioma (more than $4 \mathrm{~cm}$ ) are symptomatic in $40 \%$ of cases. Symptoms are rare and may include abdominal pain, early satiety, anorexia, nausea [55]. Contrast enhanced CT or MRI are the best modalities for the diagnosis. The risk of rupture is minimal and does not justify resection. Other complications include thrombosis, sclerosis, and calcification. The Kasabach-Meritt syndrome (consumption coagulopathy) and the Bornman-TerblancheBlumgart syndrome (fever and abdominal pain) constitute an extremely rare complication [56].

\section{Hepatic Adenoma}

Adenoma occurs in women with oral contraception use more than 5 years or in diabetic patients [57]. Multiple adenomas are associated with glycogen storage disease type I and type III and adenomatosis (more than 10 adenomas) is observed with anabolic or androgenic steroids consumption [58, 59], abdominal discomfort is common. The lesion is hypo- to hyper- echoic on US and hypo- to hyper- dense on CT. MRI is not specific [60]. The lesions are often smaller than $8 \mathrm{~cm}$ but may be larger than $15 \mathrm{~cm}$. Five percent of hepatic adenomas transform to HCC [61]. Beta-catenin immuno staining may be useful for diagnosis [62]. Spontaneous rupture and hemoperitoneum occur in $10 \%$ of cases, especially during menstruation, pregnancy or post partum. Most herpetologists advocate resection and discontinuation of oral contraception [63].

\section{Focal fatty infiltration of the liver}

In $10 \%$ of patients with fatty liver, fat accumulates focally or shows focal sparing, usually in the anteromedial segment of the left lobe. These patients usually have diabetes, hyperlipidemia, and obesity, drink alcohol or take steroids [64]. On US, fat is hyper echoic. On CT, it has low attenuation. Focal fatty liver does not displace intrahepatic vessels. The gold standard imaging technique is MRI with increased signal on T1 sequence [65]. Fat suppression techniques are also very promising.

Other very rare benign tumors in cirrhosis includes: hepatobiliary cyst adenoma, bile duct adenoma (cholangioma), biliary papillomatosis, lipomas, myolipomas, angiomyolipomas, schwannomas, neurofibromas and chondromas, inflammatory pseudotumor, and pseudo-lesions.

\section{Liver biopsy versus liver mass resection}

Before hepatic resection, lesions should be measured, counted and localized to the Couinaud segments. Their relationship to major anatomic structures (portal vein, hepatic artery, inferior vena cava, hepatic vein) should be detailed [66]. If malignancy is obvious, biopsy should be avoided because of possible tumor seeding [67]. Liver histology by true cut needle biopsy is much more profitable than fine needle aspiration and cytological examination but has several disadvantages: if the tumor is small (less than $2 \mathrm{~cm}$ ), a second attempt should be made in $20 \%$ of cases [68], bleeding is mild in $1 \%$ and severe in $0.1 \%$. In $10 \%$ of cases a firm diagnosis is not established and resection should be performed.

The Child-Pugh score helps selecting which patients should undergo hepatic resection. Survival depends on the regenerative potential and the presence of cirrhosis [69]. Traditionally, cirrhosis is a contraindication to hepatic resection because of high mortality rate $(20 \%)$. The dilemma arises when patients with cirrhosis require a hepatic resection. The problem is that $10-20 \%$ of patients with cirrhosis have primary hepatic malignancy. Moreover, $80-90 \%$ of patients with HCC and $10-20 \%$ of patients with cholangiocarcinoma have cirrhosis. The operative mortality of extensive hepatic resection in patients without cirrhosis is between $1-10 \%$ [70].

Patients with compensated cirrhosis may benefit from liver resection, radiofrequency ablation (RFA), or transarterial chemoembolisation (TACE). Patients with decompensated cirrhosis would probably have no survival benefit [71]. In selected patients, liver transplantation may be more beneficial.

\section{Conclusions}

There are no clear cut indications when to use which imaging modality in differentiating benign from malignant lesion. Choice of modality depends on many factors including cirrhosis, steatosis, and the number of nodules. The most likely diagnosis of liver mass in cirrhotic patients is HCC, followed by high and low grade dysplastic nodule, and cholangiocarcinoma. Ultrasound is often the first diagnostic imaging and contrast enhanced US may answer your question. MRI or CT often allows the correct diagnosis of a primary 
liver tumor. PET/CT using FDG mainly used to exclude regional and distant metastasis in primary liver tumors. In cirrhotic liver, main objective of the biopsy of a nodule less than $2 \mathrm{~cm}$ is to ascertain a diagnosis of $\mathrm{HCC}$, which is now improved by the use of specific molecular markers. In noncirrhotic liver, liver biopsy is required for the differential diagnosis of liver cell adenoma with HCC, and cholangiocarcinoma with liver metastasis, respectively.

\section{Abbreviations}

FNAB, Fine needle aspiration biopsy; FNCB, fine needle core biopsy, HCC, hepatocellular carcinoma; AFP: alpha-fetoprotein; CT: computed tomography; MRI: magnetic resonance imaging; DN: dysplastic nodule ; RN: regenerative nodule ; FNH, focal nodular hyperplasia; FFL, focal fatty liver; DN, dysplastic nodule; RN, regenerative nodule; CP, Child-Pugh's score, OLT, orthotropic liver transplantation; AFP, alpha feto protein; NRH, Nodular Regenerative Hyperplasia; PNT, Partial Nodular Transformation; RFA, radiofrequency ablation; PEI, percutaneous ethanol injection; (TACE), hepatic arterial chemoembolisation; DIA, Digital image analysis; FISH, fluorescent in situ hybridization.

\section{References}

1. van den Bos IC, Hussain SM, de Man RA, Zondervan PE, Ijzermans JN, Krestin GP. Primary hepatocellular lesions: imaging findings on state-of-the-art magnetic resonance imaging, with pathologic correlation. Curr Probl Diagn Radiol 2008;37(3):104-114.

2. Giannitrapani L, Soresi M, La Spada E, Cervello M, D'Alessandro N, Montalto G. Sex hormones and risk of liver tumor. Ann N Y Acad Sci 2006;1089(228-236.

3. Dogliotti E. Molecular mechanisms of carcinogenesis by vinyl chloride. Ann Ist Super Sanita 2006;42(2):163169.

4. Shaib Y, El-Serag HB. The epidemiology of cholangiocarcinoma. Semin Liver Dis 2004;24(2):115-125.

5. Borentain P, Gerolami R, Dodero F, Chrestian MA, Quillichini F, Ardissone J, Perrimond H, et al. [High serum alkaline phosphatase level revealing a liver adenoma]. Gastroenterol Clin Biol 2006;30(2):304-306.

6. Hussain SM, Semelka RC. Liver masses. Magn Reson Imaging Clin N Am 2005;13(2):255-275.

7. Seitz G. [Why are metastases in cirrhotic livers so rare?]. Ultraschall Med 1989;10(3):123-126.

8. Forner A, Vilana R, Ayuso C, Bianchi L, Sole M, Ayuso JR, Boix L, et al. Diagnosis of hepatic nodules $20 \mathrm{~mm}$ or smaller in cirrhosis: Prospective validation of the noninvasive diagnostic criteria for hepatocellular carcinoma.
Hepatology 2008;47(1):97-104.

9. Grazi GL, Mazziotti A, Legnani C, Jovine E, Miniero R, Gallucci A, Palareti G, et al. The role of tumor markers in the diagnosis of hepatocellular carcinoma, with special reference to the des-gamma-carboxy prothrombin. Liver Transpl Surg 1995;1(4):249-255.

10. Ramage JK, Donaghy A, Farrant JM, Iorns R, Williams R. Serum tumor markers for the diagnosis of cholangiocarcinoma in primary sclerosing cholangitis. Gastroenterology 1995;108(3):865-869.

11. Caturelli E, Solmi L, Anti M, Fusilli S, Roselli P, Andriulli A, Fornari F, et al. Ultrasound guided fine needle biopsy of early hepatocellular carcinoma complicating liver cirrhosis: a multicentre study. Gut 2004;53(9):13561362 .

12. Sherman M. Alphafetoprotein: an obituary. J Hepatol 2001;34(4):603-605.

13. Balci NC, Befeler AS, Leiva P, Pilgram TK, Havlioglu $\mathrm{N}$. Imaging of liver disease: comparison between quadruple-phase multidetector computed tomography and magnetic resonance imaging. J Gastroenterol Hepatol 2008;23(10):1520-1527.

14. Hori M, Murakami T, Kim T, Takahashi S, Oi H, Tomoda K, Narumi Y, et al. Sensitivity of double-phase helical CT during arterial portography for detection of hypervascular hepatocellular carcinoma. J Comput Assist Tomogr 1998;22(6):861-867.

15. van Kouwen MC, Oyen WJ, Nagengast FM, Jansen JB, Drenth JP. FDG-PET scanning in the diagnosis of gastrointestinal cancers. Scand J Gastroenterol Suppl 2004241):85-92.

16. Kanematsu M, Hoshi H, Yamada T, Murakami T, Kim T, Kato M, Yokoyama R, et al. Small hepatic nodules in cirrhosis: ultrasonographic, CT, and MR imaging findings. Abdom Imaging 1999;24(1):47-55.

17. Gandhi SN, Brown MA, Wong JG, Aguirre DA, Sirlin CB. MR contrast agents for liver imaging: what, when, how. Radiographics 2006;26(6):1621-1636.

18. Solbiati L, Tonolini M, Cova L, et al. The role of contrast-enhanced ultrasound in the detection of focal liver lesions. Eur Radiol.2001;11:15-26.

19. de Ledinghen V, Laharie D, Lecesne R, Le Bail B, Winnock M, Bernard PH, Saric J, et al. Detection of nodules in liver cirrhosis: spiral computed tomography or magnetic resonance imaging? A prospective study of 88 nodules in 34 patients. Eur J Gastroenterol Hepatol 2002;14(2):159-165.

20. Stewart CJ, Coldewey J, Stewart IS. Comparison of fine needle aspiration cytology and needle core biopsy in the diagnosis of radiologically detected abdominal lesions. J Clin Pathol 2002;55(2):93-97.

21. Franca AV, Valerio HM, Trevisan M, Escanhoela C, Seva-Pereira T, Zucoloto S, Martinelli A, et al. Fine needle aspiration biopsy for improving the diagnostic accuracy 
of cut needle biopsy of focal liver lesions. Acta Cytol 2003;47(3):332-336.

22. Borzio M, Borzio F, Macchi R, Croce AM, Bruno S, Ferrari A, Servida E. The evaluation of fine-needle procedures for the diagnosis of focal liver lesions in cirrhosis. J Hepatol 1994;20(1):117-121.

23. Buscarini L, Fornari F, Bolondi L, Colombo P, Livraghi T, Magnolfi F, Rapaccini GL, et al. Ultrasound-guided fine-needle biopsy of focal liver lesions: techniques, diagnostic accuracy and complications. A retrospective study on 2091 biopsies. J Hepatol 1990;11(3):344-348.

24. Edoute Y, Malberger E, Tibon-Fishe O, Assy N. Nonimaging-guided fine-needle aspiration of liver lesions: a retrospective study of 279 patients. World J Gastroenterol 1999;5(2):98-102.

25. Capurro M, Wanless IR, Sherman M, Deboer G, Shi W, Miyoshi E, Filmus J. Glypican-3: a novel serum and histochemical marker for hepatocellular carcinoma. Gastroenterology 2003;125(1):89-97.

26. Tang W, Guo Q, Qu X, Inagaki Y, Seyama Y, Midorikawa Y, Gai R, et al. KL-6 mucin is a useful immunohistochemical marker for cholangiocarcinoma. Oncol Rep 2007;17(4):737-741.

27. Bruix J, Sherman M. Management of hepatocellular carcinoma. Hepatology 2005;42(5):1208-1236.

28. Ryder SD. Guidelines for the diagnosis and treatment of hepatocellular carcinoma (HCC) in adults. Gut 2003;52 Suppl 3(iii1-8.

29. Caturelli E, Biasini E, Bartolucci F, Facciorusso D, Decembrino F, Attino V, Bisceglia M. Diagnosis of hepatocellular carcinoma complicating liver cirrhosis: utility of repeat ultrasound-guided biopsy after unsuccessful first sampling. Cardiovasc Intervent Radiol 2002;25(4):295299.

30. Bruix J, Sherman M, Llovet JM, Beaugrand M, Lencioni R, Burroughs AK, Christensen E, et al. Clinical management of hepatocellular carcinoma. Conclusions of the Barcelona-2000 EASL conference. European Association for the Study of the Liver. J Hepatol 2001;35(3):421430.

31. Rapaccini GL, Pompili M, Caturelli E, Anti M, Aliotta A, Cedrone A, Amadei E, et al. Focal ultrasound lesions in liver cirrhosis diagnosed as regenerating nodules by fine-needle biopsy. Follow-up of 12 cases. Dig Dis Sci 1990;35(4):422-427.

32. Mor E, Kaspa RT, Sheiner P, Schwartz M. Treatment of hepatocellular carcinoma associated with cirrhosis in the era of liver transplantation. Ann Intern Med 1998;129(8):643-653.

33. Cedrone A, Covino M, Caturelli E, Pompili M, Lorenzelli G, Villani MR, Valle D, et al. Utility of alpha-fetoprotein (AFP) in the screening of patients with virus-related chronic liver disease: does different viral etiology influence AFP levels in HCC? A study in 350 western patients. Hepatogastroenterology 2000;47(36):16541658.

34. Sherman M. Screening for hepatocellular carcinoma. Hepatol Res 2007;37 Suppl 2(S152-165.

35. Simonetti RG, Camma C, Fiorello F, Politi F, D'Amico G, Pagliaro L. Hepatocellular carcinoma. A worldwide problem and the major risk factors. Dig Dis Sci 1991;36(7):962-972.

36. Reddy KR, Schiff ER. Approach to a liver mass. Semin Liver Dis 1993;13(4):423-435.

37. Terminology of nodular hepatocellular lesions. International Working Party. Hepatology 1995;22(3):983-993.

38. Hussain SM, Zondervan PE, JN IJ, Schalm SW, de Man RA, Krestin GP. Benign versus malignant hepatic nodules: MR imaging findings with pathologic correlation. Radiographics 2002;22(5):1023-1036; discussion 10371029.

39. Landis SH, Murray T, Bolden S, Wingo PA. Cancer statistics, 1998. CA Cancer J Clin 1998;48(1):6-29.

40. Shin HR, Lee CU, Park HJ, Seol SY, Chung JM, Choi $\mathrm{HC}$, Ahn YO, et al. Hepatitis B and C virus, Clonorchis sinensis for the risk of liver cancer: a case-control study in Pusan, Korea. Int J Epidemiol 1996;25(5):933-940.

41. de Groen PC, Gores GJ, LaRusso NF, Gunderson LL, Nagorney DM. Biliary tract cancers. N Engl J Med 1999;341(18):1368-1378.

42. Nichols JC, Gores GJ, LaRusso NF, Wiesner RH, Nagorney DM, Ritts RE, Jr. Diagnostic role of serum CA 19-9 for cholangiocarcinoma in patients with primary sclerosing cholangitis. Mayo Clin Proc 1993;68(9):874-879.

43. Nesbit GM, Johnson CD, James EM, MacCarty RL, Nagorney DM, Bender CE. Cholangiocarcinoma: diagnosis and evaluation of resectability by $\mathrm{CT}$ and sonography as procedures complementary to cholangiography. AJR Am J Roentgenol 1988;151(5):933-938.

44. Tillich M, Mischinger HJ, Preisegger KH, Rabl H, Szolar DH. Multiphasic helical CT in diagnosis and staging of hilar cholangiocarcinoma. AJR Am J Roentgenol 1998;171(3):651-658.

45. Ustundag Y, Bayraktar Y. Cholangiocarcinoma: a compact review of the literature. World J Gastroenterol 2008;14(42):6458-6466.

46. Schmitt A, Gilden DJ, Saint S, Moseley RH. Clinical problem-solving. Empirically incorrect. N Engl J Med 2006;354(5):509-514.

47. Zornoza J, Ginaldi S. Computed tomography in hepatic lymphoma. Radiology 1981;138(2):405-410.

48. El-Serag HB, Mason AC. Rising incidence of hepatocellular carcinoma in the United States. N Engl J Med 1999;340(10):745-750.

49. Tsao JI, DeSanctis J, Rossi RL, Oberfield RA. Hepatic malignancies. Surg Clin North Am 2000;80(2):603-632.

50. Schwartz L, Brody L, Brown K, Covey A, Tuorto S, Mazumdar M, Riedel E, et al. Prospective, blinded com- 
parison of helical CT and CT arterial portography in the assessment of hepatic metastasis from colorectal carcinoma. World J Surg 2006;30(10):1892-1899; discussion 1900-1891.

51. Leen E, Ceccotti P, Moug SJ, Glen P, MacQuarrie J, Angerson WJ, Albrecht T, et al. Potential value of contrastenhanced intraoperative ultrasonography during partial hepatectomy for metastases: an essential investigation before resection? Ann Surg 2006;243(2):236-240.

52. Nagaoka S, Itano S, Ishibashi M, Torimura T, Baba K, Akiyoshi J, Kurogi J, et al. Value of fusing PET plus CT images in hepatocellular carcinoma and combined hepatocellular and cholangiocarcinoma patients with extrahepatic metastases: preliminary findings. Liver Int 2006;26(7):781-788.

53. Wee A. Fine needle aspiration biopsy of the liver: Algorithmic approach and current issues in the diagnosis of hepatocellular carcinoma. Cytojournal 2005;2:7.

54. Takagi H. Diagnosis and management of cavernous hemangioma of the liver. Semin Surg Oncol 1985;1(1):1222.

55. Trastek VF, van Heerden JA, Sheedy PF, 2nd, Adson MA. Cavernous hemangiomas of the liver: resect or observe? Am J Surg 1983;145(1):49-53.

56. Sewell JH, Weiss K. Spontaneous rupture of hemangioma of the liver. A review of the literature and presentation of illustrative case. Arch Surg 1961;83(729-733.

57. Rabe T, Feldmann K, Grunwald K, Runnebaum B. Liver tumours in women on oral contraceptives. Lancet 1994;344(8936):1568-1569.

58. Labrune P, Trioche P, Duvaltier I, Chevalier P, Odievre M. Hepatocellular adenomas in glycogen storage disease type I and III: a series of 43 patients and review of the literature. J Pediatr Gastroenterol Nutr 1997;24(3):276279.

59. Grazioli L, Federle MP, Brancatelli G, Ichikawa T, Olivetti L, Blachar A. Hepatic adenomas: imaging and pathologic findings. Radiographics 2001;21(4):877892; discussion 892-874.

60. Kume N, Suga K, Nishigauchi K, Shimizu K, Matsuna- ga N. Characterization of hepatic adenoma with atypical appearance on CT and MRI by radionuclide imaging. Clin Nucl Med 1997;22(12):825-831.

61. Colli A, Fraquelli M, Massironi S, et al. Elective surgery for benign liver tumors. Cochrane Database Syst Rev.2007;CD005164.

62. Micchelli ST, Vivekanandan P, Boitnott JK, Pawlik TM, Choti MA, Torbenson M. Malignant transformation of hepatic adenomas. Mod Pathol 2008;21(4):491-497.

63. Lizardi-Cervera J, Cuellar-Gamboa L, Motola-Kuba D. Focal nodular hyperplasia and hepatic adenoma: a review. Ann Hepatol 2006;5(3):206-211.

64. Perlemuter G, Bigorgne A, Cassard-Doulcier AM, Naveau S. Nonalcoholic fatty liver disease: from pathogenesis to patient care. Nat Clin Pract Endocrinol Metab 2007;3(6):458-469.

65. Karcaaltincaba M, Akhan O. Imaging of hepatic steatosis and fatty sparing. Eur J Radiol 2007;61(1):33-43.

66. Buc E, Lesurtel M, Belghiti J. Is preoperative histological diagnosis necessary before referral to major surgery for cholangiocarcinoma? HPB (Oxford) 2008;10(2):98105.

67. Takamori R, Wong LL, Dang C, Wong L. Needle-tract implantation from hepatocellular cancer: is needle biopsy of the liver always necessary? Liver Transpl 2000;6(1):67-72.

68. Francque SM, De Pauw FF, Van den Steen GH, Van Marck EA, Pelckmans PA, Michielsen PP. Biopsy of focal liver lesions: guidelines, comparison of techniques and cost-analysis. Acta Gastroenterol Belg 2003;66(2):160-165.

69. Assy N, Pruzansky Y, Gaitini D, Shen Orr Z, Hochberg Z, Baruch Y. Growth hormone-stimulated IGF-1 generation in cirrhosis reflects hepatocellular dysfunction. $\mathrm{J}$ Hepatol 2008;49(1):34-42.

70. Bouwman DL, Walt AJ. Current status of resection for hepatic neoplasms. Semin Liver Dis 1983;3(3):193-202.

71. Frezza EE. Therapeutic management algorithm in cirrhotic and noncirrhotic patients in primary or secondary liver masses. Dig Dis Sci 2004;49(5):866-871. 